\title{
Sharing Virtual Histology Images Worldwide - The Virtual Microscopy Database
}

\section{Michael Hortsch*}

Departments of Cell and Developmental Biology and Learning Health Sciences, University of Michigan, USA

Ever since Anton van Leeuwenhoek started to use his primitive microscopes for viewing living organisms in the 1670s technological advances in microscopy have expanded our knowledge about biological structures. Technological innovations have not only furthered the work of researchers analyzing biological tissues and cells, but have also left their mark on the teaching of biological and medical disciplines, with histology representing the original science of structural cell and tissue biology. For about one century, the standard way of teaching histology and pathology required banks of light microscopes in combination with sets of glass slides containing stained tissue sections. Over the last 25 years, virtual microscopy has become a popular alternative to classical light microscopy and is now progressively replacing the traditional laboratory-based method of teaching histology and pathology [1-4].

For virtual microscopy, high-quality histology or pathology glass slides are scanned at high resolution using a special microscope setup with a powerful digital camera. The resulting large image file (sometimes exceeding several GBs) is stored on a central computer server and can be displayed on computer screens by students connected by the Internet or a local network. As only a small part of the entire digital image file is downloaded, students can quickly pan across the image and zoom in or out to view smaller details or get an overview of the entire slide. All students have equal access to the same collection of high-quality slide material.

Many new schools and universities adopt virtual microscopy from the beginning and also established institutions are switching more and more to a virtual microscopy approach [5-7]. However, good glass slides are often difficult to come by or are unavailable altogether. In addition, slide digitization requires dedicated equipment that is usually not available at most teaching or research institutions. Although digital image files can easily be shared, an efficient way to distribute and exchange virtual microscopy image files has been missing until recently.

Such a resource now exists in the form of an online file sharing database called Virtual Microscopy Database or VMD. The project was initiated and is now administrated by three experienced histology educators, Dr. Haviva Goldman (Drexel University), Dr. Lisa Lee (University of Colorado), and the author of this editorial. A grant awarded by the American Association of Anatomists (AAA; https:// www.anatomy.org) supported the initial creation of the VMD. mbf Bioscience (http://www.mbfbioscience.com) donated the free use of their virtual slide viewer and database management software to the VMD project.

The VMD resource opened in April 2017 and can be accessed via the Internet at http://www.virtualmicroscopydatabase.org (Figure 1). However, the viewing and downloading of VMD virtual image files contained requires a simple onetime registration. The registration and use of the VMD is free of charge. The VMD database is not constructed for general student use or for running a course off its website. Therefore, only educators and researchers are able to register and access the site's image files. Currently, the VMD site offers $>2500$ virtual image files, most are either light or electron micrographs of normal cells and tissues. New images and collections are constantly being added. A number of pathological and immuno-stained specimens are also available. The available files are currently organized into 15 collections, donated by 15 different universities located in four different countries. VMD users can locate specific images/image topics by perusing collection subfolders or by using a database-wide search function with keywords of their choice. The copyright of all images in the VMD remains with the donating individual or institution and all image files are made available to VMD users under an attribution-share alikenoncommercial Creative Commons license (https://creativecommons. org/licenses/by-nc-sa/4.0/). That license excludes any commercial use of VMD images without the written permission of the original copyright holder.

At the current time, the VMD has almost 500 registered users from 56 different countries. Registered users are able to examine all VMD virtual images by scanning and zooming in/out using the Biolucida $^{\circledR}$ viewer (http://www.biolucida.net/viewer/). In addition, they can screen-grab any image or download the image files for their local use, independent of the VMD website. Many of the images have supplementary information, such as histological stain and the organ and species from which the tissue section originated. VMD images can be used as lecture illustrations, for students' laboratory sessions, for the creation of supplementary course material, for the generation of quiz and examination questions, and for other research and educational purposes.

The efficient use of a resource like the VMD requires a certain level of technical infrastructure, like fast Internet access, a local network connected to a computer server, the availability of computers for teachers and students. However, these hardware resources become more and more standard equipment, even at schools in developing countries. This makes virtual microscopy teaching approaches feasible at almost any school.

New resources, like the VMD, will allow many histology and pathology educators to elevate the quality of their teaching. They are now able to expose their students to a broad variety of high-quality images and to introduce new methodologies to their classrooms. It will also facilitate the introduction of active and collaborative learning approaches to the instruction of histology and pathology [8-10]. As evidenced by the worldwide adaptation of virtual microcopy, not only

*Corresponding author: Michael Hortsch, University of Michigan, Department of Cell and Developmental Biology, 109 Zina Pitcher Place, Ann Arbor, MI 481092200, USA, E-mail: hortsch@umich.edu

Received October 08, 2017; Accepted October 28, 2017; Published November 05, 2017

Citation: Hortsch M (2017) Sharing Virtual Histology Images Worldwide The Virtual Microscopy Database. J Cytol Histol 8: e120. doi: 10.4172/21577099.1000e120

Copyright: (c) 2017 Hortsch M. This is an open-access article distributed under the terms of the Creative Commons Attribution License, which permits unrestricted use, distribution, and reproduction in any medium, provided the original author and source are credited. 
Citation: Hortsch M (2017) Sharing Virtual Histology Images Worldwide - The Virtual Microscopy Database. J Cytol Histol 8: e120. doi: 10.4172/2157$7099.1000 \mathrm{e} 120$

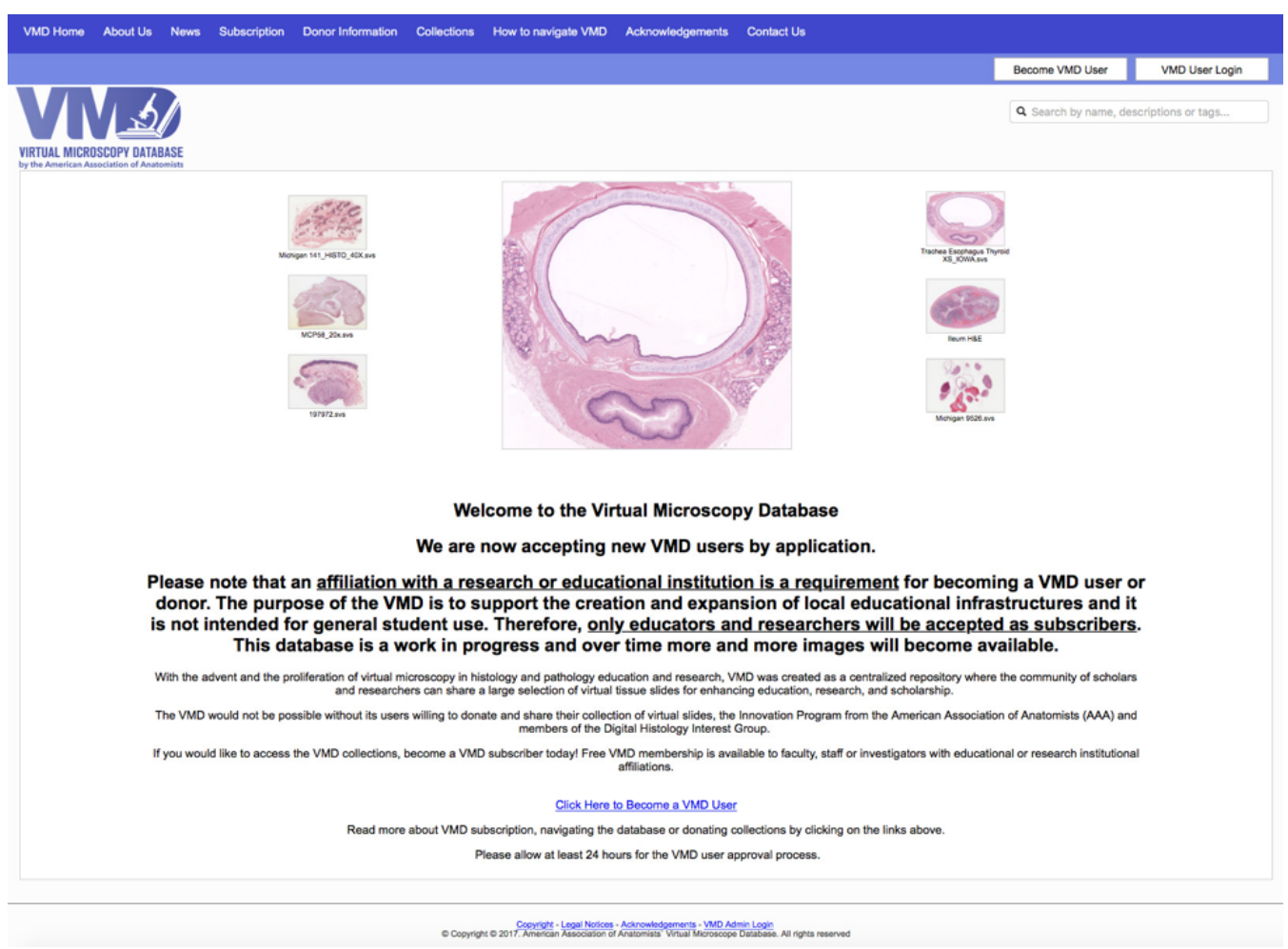

Figure 1: Home page of the virtual microscopy database at http://www.virtualmicroscopydatabase.org

basic research and clinical applications, but also the teaching of cellular structures and the organization of living organisms benefits from technological advances in microscopy.

The creation of the new VMD resource was made possible by the tireless work of my co-administrators Drs. Lee and Goldman. Without their initiative, the VMD would be no more than a lofty dream. Special thanks are owed to the leadership, the administrative team, and the membership of the American Association of Anatomist for supporting the VMD initiative. The VMD administrators are also grateful for the generous assistance provided by mbf Bioscience. Many thanks also go to all individuals and institutions, which made their virtual slide collections available through the VMD to users worldwide.

\section{References}

1. Coleman R (2009) Can histology and pathology be taught without microscopes? The advantages and disadvantages of virtual histology. Acta Histochem 111: 1-4.

2. Drake RL, McBride JM, Lachman N, Pawlina W (2009) Medical education in the anatomical sciences: The winds of change continue to blow. Anat Sci Educ 2: 253-259.
3. Bloodgood RA, Ogilvie RW (2006) Trends in histology laboratory teaching in United States medical schools. Anat Rec B New Anat 289: 169-175.

4. Hortsch M (2013) From Microscopes to Virtual Reality-How Our Teaching of Histology is Changing. J Cytol Histol 4: e108.

5. Heidger Jr PM, Dee F, Consoer D, Leaven T, Duncan J, Kreiter C (2002) Integrated approach to teaching and testing in histology with real and virtual imaging. Anat Rec 269: 107-112.

6. Krippendorf BB, Lough J (2005) Complete and rapid switch from light microscopy to virtual microscopy for teaching medical histology. Anat Rec B New Anat 285: 19-25.

7. Patel SG, Rosenbaum BP, Chark DW, Lambert HW (2006) Design and implementation of a web-based, database-driven histology atlas: technology at work. Anat Rec B New Anat 289: 176-183.

8. Lei LW, Winn W, Scott C, Farr A (2005) Evaluation of computer-assisted instruction in histology: effect of interaction on learning outcome. Anat Rec B New Anat 284: 28-34.

9. Triola MM, Holloway WJ (2011) Enhanced virtual microscopy for collaborative education. BMC Med Educ 11: 4.

10. Bloodgood RA (2012) Active learning: A small group histology laboratory exercise in a whole class setting utilizing virtual slides and peer education. Anat Sci Educ 5: 367-373. 